\title{
Orbital Ridge
}

National Cancer Institute

\section{Source}

National Cancer Institute. Orbital Ridge. NCI Thesaurus. Code C82953.

The bony elevation located beneath the eyebrow. 